\title{
Reducing the sampling frequency for the control of the switched reluctance machine
}

\author{
Xavier Rain*, Mickaël Hilairet*, member, IEEE, Antoni Arias ${ }^{\circledR}$, member, IEEE \\ *Laboratoire de Génie Electrique de Paris (LGEP) / SPEE-Labs, \\ CNRS UMR 8507; SUPELEC; Université Pierre et Marie Curie P6; Université Paris-Sud 11; \\ 11 rue Joliot Curie, Plateau de Moulon, F 91192, Gif sur Yvette CEDEX \\ ${ }^{\diamond}$ Universitat Politecnica de Catalunya. colom 1.08222 Terrassa.Catalonia.Spain \\ Email: xavier.rain@lgep.supelec.fr ; mickael.hilairet@lgep.supelec.fr ; antoni.arias@upc.edu
}

\begin{abstract}
This paper presents two solutions for dramatically reduce the sampling frequency and therefore the $\mathrm{CPU}$ demand while keeping the same performance in terms of torque ripple and efficiency on a SRM. The problem of a low sampling frequency with a regular control is first highlighted. Then, two different solutions are proposed for the self switching's function. Such solutions tries to magnetize the stator phase at an accurate instant in order to reduce the inherent torque ripple. Simulations results on a 8/6 SRM corroborate the validity of the proposed solutions and show the improvements of its performance.
\end{abstract}

Index Terms-Switched reluctance machine, sampling period enlargement, self switching, torque ripple, efficiency.

\section{INTRODUCTION}

$\mathbf{T}$ HE switched reluctance machines (SRM) had attracted many researchers over the last decade. This is certainly due to its numerous advantages such as simple and robust construction, high-speed and high-temperature performance, low costs, and fault tolerant control capabilities [1], [2]. The performance of SRM has been enhanced greatly due to advances in power electronics and computer science. Nowadays, SRM are under consideration in various applications requiring high performances such as in electric vehicle propulsion [3], [4], automotive starter-generators [1], [2] and aerospace applications [5], [6].

However, several disadvantages like acoustic noise generation, torque ripple, nonlinear electromagnetic characteristics, the strong dependence on the rotor position, requirement of a high powerful processor are limiting its utilization compared to other type of machines.

For cost reasons, manufacturers usually try to use economic processors, i.e. with a low sampling frequency. Therefore, the aim of this paper is to show that it is possible to control an SRM with no degradation of its performances, using low powerful processors.

This paper is organized in three sections as follows: in the first section, the paper recalls the SRM's control. In the second section, the influence of a low sampling frequency is highlighted. Then, in the third section, two solutions are proposed for the self switching function generator, avoiding the significant performance degradation when the sampling frequency is low.

\section{SRM'S CONTROL}

Fig.1 illustrates a SRM's control strategy based on an average torque control [7], [8]. The SRM's control consists of 4 functions: speed control, torque control strategy, a switch control signal generator and current control. The last 3 blocks compose an open-loop average torque control. As with any type of electrical machine, the speed controller's output provides the electromagnetic required torque $T_{e m}^{*}$.

In this strategy, the reference torque is considered as an average torque over one conducting period. It is controlled indirectly by adjusting the three fundamental variables, i.e., reference-phase current $I^{*}$, turn-on angle $\theta_{o n}$, and turn-off angle $\theta_{\text {off } f}$. One important feature of this regular controller is that the reference-phase current is constant over one excitation period. Thereby, this control is also called "square wave control". Many combinations of these control variables are possible to control the SRM at one specific torque-speed operating point. However, one suitable combination for one speed-torque operating point should be chosen, based on the desired optimization aim, i.e. efficiency or torque ripple level [7], [8].

An optimal set of the control variables over the entire operating range can be obtained by means of a Finite Element Model [10]. The torque translation into a current reference is located in a look-up table. Linear data interpolation is performed on-line to compute the optimal control parameters. Many classical SRM torque controllers use this approach and rely on look-up tables of the control parameters.

The current's controller implemented is an "hybrid" current controller [9], which is an association of a ON-OFF controller and IP (Integral-Proportional) controller. Therefore, it combines the main advantages of both: high dynamics, good robustness for the ON-OFF controller and low current ripples for the IP controller.

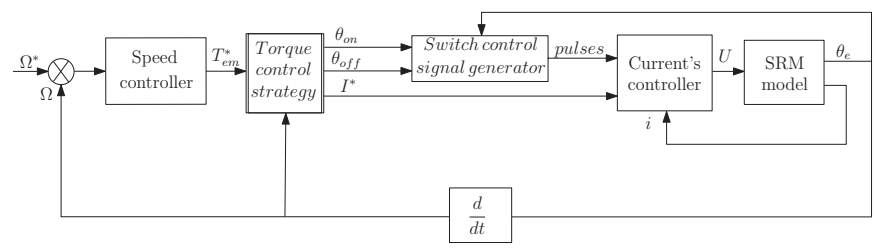

Fig. 1. SRM's speed control. 

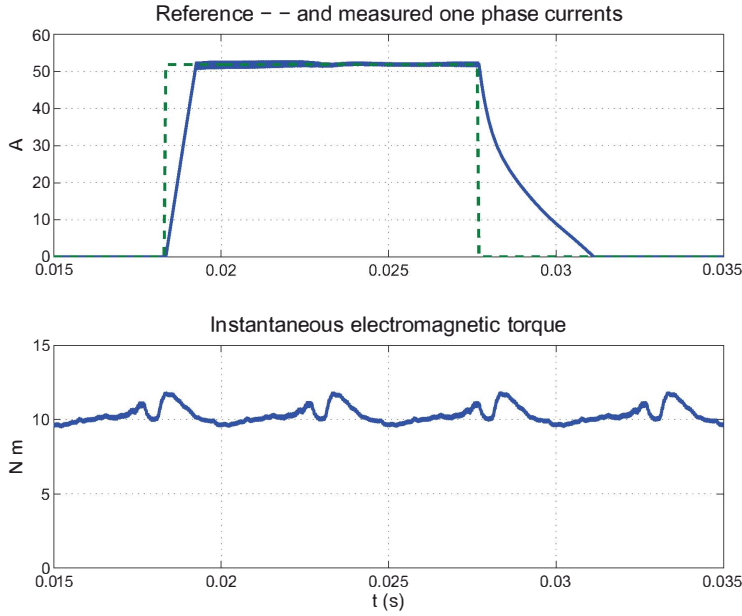

Fig. 2. Phase currents and instantaneous electromagnetic torque at $\Omega=500$ $\mathrm{rpm}$ and $T_{e m}^{*}=10 \mathrm{~N} . \mathrm{m}-T_{s}=50 \mu \mathrm{s}$.
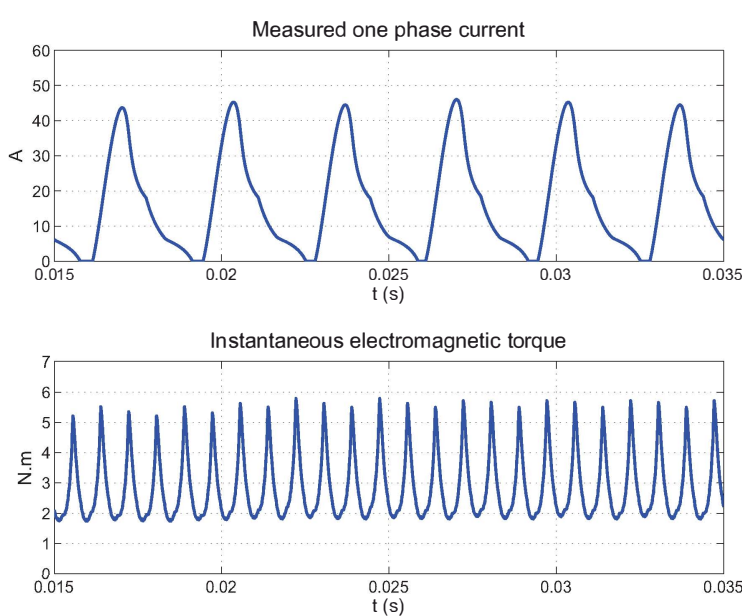

Fig. 3. Phase current and instantaneous electromagnetic torque at $\Omega=3000$ rpm and $T_{e m}^{*}=3 \mathrm{~N} . \mathrm{m}-T_{s}=50 \mu \mathrm{s}$.

\section{CONTROL ALGORITHMS IMPLEMENTATION}

\section{A. Introduction}

Currently, SRM drives are digitally implemented with the use of high speed and high power capability processors which have friendly developments tools based on high level languages and compilers. On the contrary, a part of the SRM's control could also be made at a hardware and low level [11], using an analog controller or an FPGA (Field Programmable Gate Array) programmed on a Hardware Description Language which uses a fixed-point implementation [12]. This latter is principally characterized by a very low sampled period, a development time much longer than the floating points platforms mentioned before.

The speed control can be sampled at a high period (i.e. $1 \mathrm{~ms}$ ) because the mechanical's dynamic is low, while the self switching and current control must be sampled at a low period (i.e. $50 \mu \mathrm{s}$ ) because the electrical dynamic is high.

In this paper, it is proposed different solutions (software and hardware) to maintain the SRM's performances when the sampling period of the processor is dramatically increase.
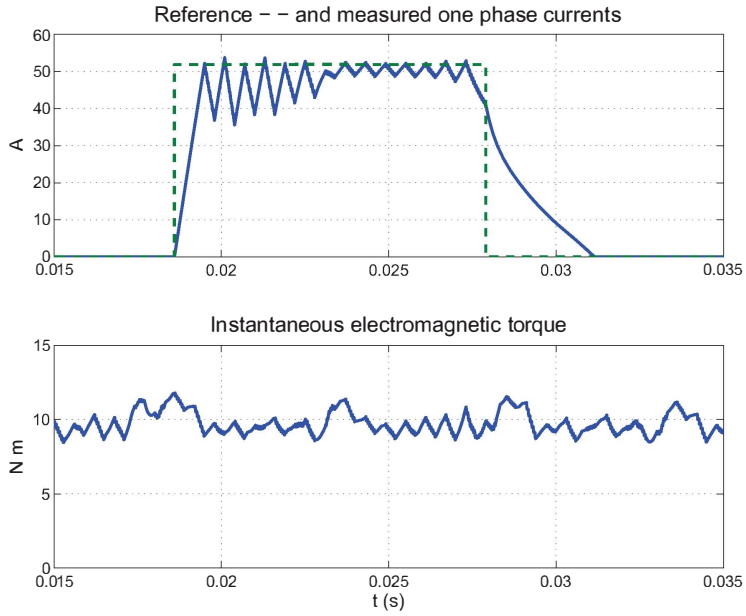

Fig. 4. Phase currents and instantaneous electromagnetic torque at $\Omega=500$ $\mathrm{rpm}$ and $T_{e m}^{*}=10 \mathrm{~N} . \mathrm{m}-T_{s}=300 \mu \mathrm{s}$.
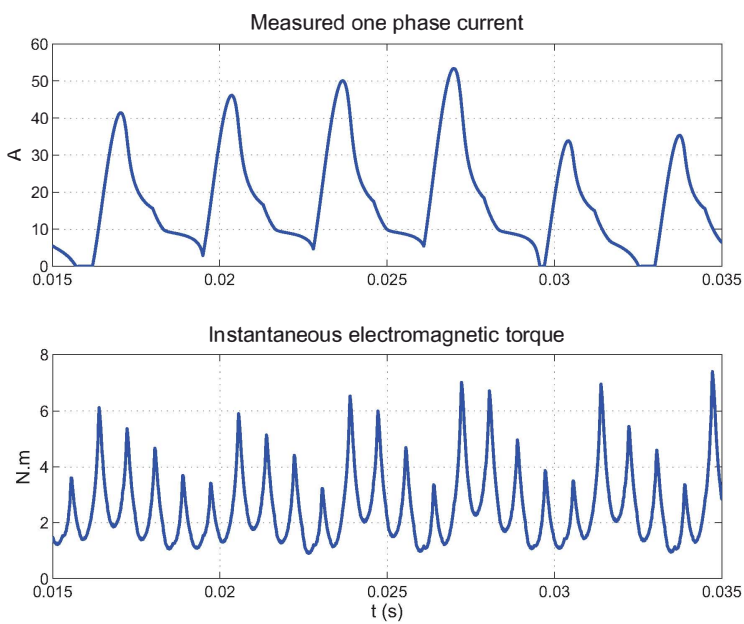

Fig. 5. Phase current and instantaneous electromagnetic torque at $\Omega=3000$ $\mathrm{rpm}$ and $T_{e m}^{*}=3 \mathrm{~N} . \mathrm{m}-T_{s}=300 \mu \mathrm{s}$.

\section{B. Sampling period influence on the SRM's performance}

SRM's characteristics are given in table II. Figs. 2 and 3 shows the instantaneous current on one phase and the instantaneous electromagnetic torque for two operating points $\left(\Omega=500 \mathrm{rpm} ; T_{e m}^{*}=10 \mathrm{~N} . \mathrm{m}\right)$ and $\left(\Omega=3000 \mathrm{rpm} ; T_{e m}^{*}=3\right.$ N.m). The sampling period $T_{s}$ is set to $50 \mu \mathrm{s}$. We can noticed that at $500 \mathrm{rpm}$, the current is well controlled to its reference value. Here, parameters $\left(I^{*}, \theta_{o n}, \theta_{o f f}\right)$ are optimized to reduce the torque ripple [7], [8]. At $3000 \mathrm{rpm}$, because of the increase of the back-emf, current can not reach its reference value, the supply is a full wave voltage. At this speed, parameters $\left(I^{*}\right.$, $\left.\theta_{\text {on }}, \theta_{\text {off }}\right)$ optimize the efficiency [7], [8].

Figs. 4 and 5 show the instantaneous current on one phase and the instantaneous electromagnetic torque for the same two operating points. The sampling period $T_{s}$ is now set to $300 \mu \mathrm{s}$. There is a significant deterioration on the current profile (oscillations), which leads to an important increase of the torque ripple, and also a reduction of the average electromagnetic torque. At $500 \mathrm{rpm}$ (low speed), this is due mainly to bad current's control and at $3000 \mathrm{rpm}$ (high speed), this is due mainly to the error between the desired angles $\left(\theta_{\text {on }}\right.$, 

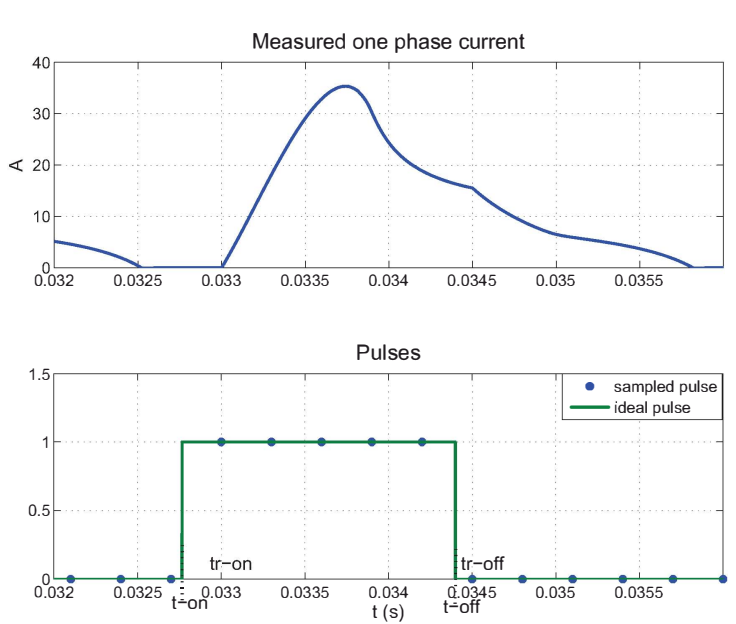

Fig. 6. Phase current, variables 'pulse' and 'ideal pulse', $\Omega=3000 \mathrm{rpm}$ and $T_{e m}^{*}=3 \mathrm{~N} \cdot \mathrm{m}-T_{s}=300 \mu \mathrm{s}$.

$\left.\theta_{o f f}\right)$ generated by the torque control, and the applied angles in a real-time context.

The first two columns of table I compare the performances according the value of the sample time. We can noticed that the global efficiency (SRM and converter) remains practically unchanged, but the torque ripple is degraded.

As a conclusion, this section showed that the sampling period has an influence on SRM's performance. The next section propose solutions for the switch control system generator, to maintain SRM's performance with large sampling period for a wide range of operating speeds.

\section{IMPROVEMENT OF SWITCH CONTROL SYSTEM GENERATOR}

\section{A. Introduction}

The switch control system generator allows the power supply of each phase, in generating a logical variable 'pulse' $(0-1)$, when the electrical angle $\theta_{e}$ is between $\theta_{\text {on }}$ and $\theta_{o f f}$. These two angles are stored in a look-up table, which has as inputs the speed $\Omega$ and mean reference torque $T_{e m}^{*}$.

Due to the sampling of this function, there is always a delay between the ideals instants $\left(t_{o n}, t_{o f f}\right)$ and the real instants $\left(t_{r o n}, t_{r o f f}\right)$ as shown in Fig. 6. The maximal time delay is equal to one sample period $T_{s}$, corresponding to a maximal electrical angle delay $\Delta \theta_{e-\max }=N_{r} \Omega T_{s}$, where $N_{r}$ is the rotor pole number and $\Omega$ is the angular rotation speed. For $\Omega=3000 \mathrm{rpm}$ and $T_{s}=300 \mu \mathrm{s}$, the maximal electrical angular delay is $32.4^{\circ}$, which is too large. Consequently, the performances are degrade as noticed in the previous section. To overcome this issue, two solutions are proposed, and discussed in the next subsection.

\section{B. First solution : self switching's anticipation}

In a real-time context, the power supply of one phase occurs after $\theta_{\text {on }}$ (i.e. $\theta_{e}[k+1]$ ). Here, it is proposed to start the power supply one sample time before (i.e. before $\theta_{\text {on }}$, at $\theta_{e}[k]$ ) in such a way that the current must have reached the same value as if the voltage supply had occurred at $\theta_{\text {on }}$ as shown in Fig. 7. Thus, equality 1 must be verified:

$$
\Delta i_{\theta_{o n}}=\Delta i_{\theta_{e}[k]}
$$

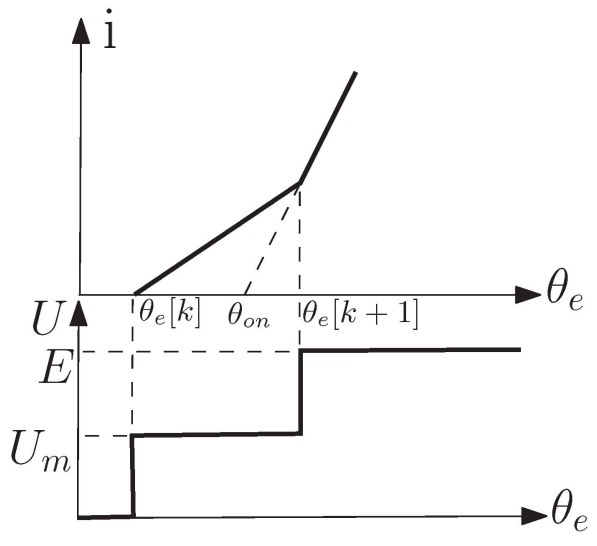

Fig. 7. Principle of the switch control signal generator anticipation Magnetization phase.

At the beginning of the magnetization's phase, the applied voltage is generally equal to the DC bus voltage $U_{d c}$ and the current is equal to zero. Moreover, the resistance voltage drop and back-emf can be neglected. In addition, the incremental inductance is approximately nearly constant at the unaligned position. Therefore, Equ. 2

$$
u=R i+L_{i n c} \frac{d i}{d t}+i N_{r} \Omega \frac{\partial L\left(\theta_{e}, i\right)}{\partial \theta_{e}}
$$

can be approximated as follows:

$$
U_{d c} \cong L_{i n c} \frac{\Delta i_{\theta_{o n}}}{\Delta t}, \quad \text { with } \quad \Delta t=\frac{\theta_{e}[k+1]-\theta_{o n}}{N_{r} \Omega}
$$

It follows immediately that the average voltage $U_{m}$ applied between the angles $\theta_{e}[k]$ and $\theta_{e}[k+1]$ is equal to:

$$
U_{m}=U_{d c} \frac{\theta_{e}[k+1]-\theta_{o n}}{N_{r} \Omega T_{s}}
$$

The computation of the predicted position $\theta_{e}[k+1]$ is:

$$
\theta_{e}[k+1]=\theta_{e}[k]+N_{r} \Omega T_{s}
$$

The same procedure stands for the demagnetization period. The average phase voltage $U_{d}$ between $\theta_{e}[k]$ and $\theta_{e}[k+1]$ is:

$$
U_{d}=-U_{d c} \frac{\theta_{e}[k+1]-\theta_{o f f}}{N_{r} \Omega T_{s}}
$$

Fig. 8 shows a simulation with the new switch control signal generator anticipation, for the operating point $(\Omega=3000 \mathrm{rpm}$, $\left.T_{e m}^{*}=3 \mathrm{~N} . \mathrm{m}\right)$. We can notice that there is a significant performance improvement in terms of torque ripple. However, at high speeds the incremental inductance and back-emf change rapidely and therefore Equ. 2 can not be simplified to Equ 6 . The results are reported on the third column of Tab. I (column $T_{s}=300 \mu$ s solution 1 ).

Moreover, at high speeds (i.e. $\Omega>3500 \mathrm{rpm}$ ), the magnetization period start despite the demagnetization period is not finish. Therefore, the machine enters in the un-controlled continuous conduction mode [9].

\section{Second solution: hardware implementation of the converter control signal}

To avoid these issues mentioned above, an other solution is proposed. The objective is to control each phase at ideals times $\left(t_{o n}, t_{o f f}\right)$ using a basic function at a hardware level.

The proposed method is composed of two steps: 

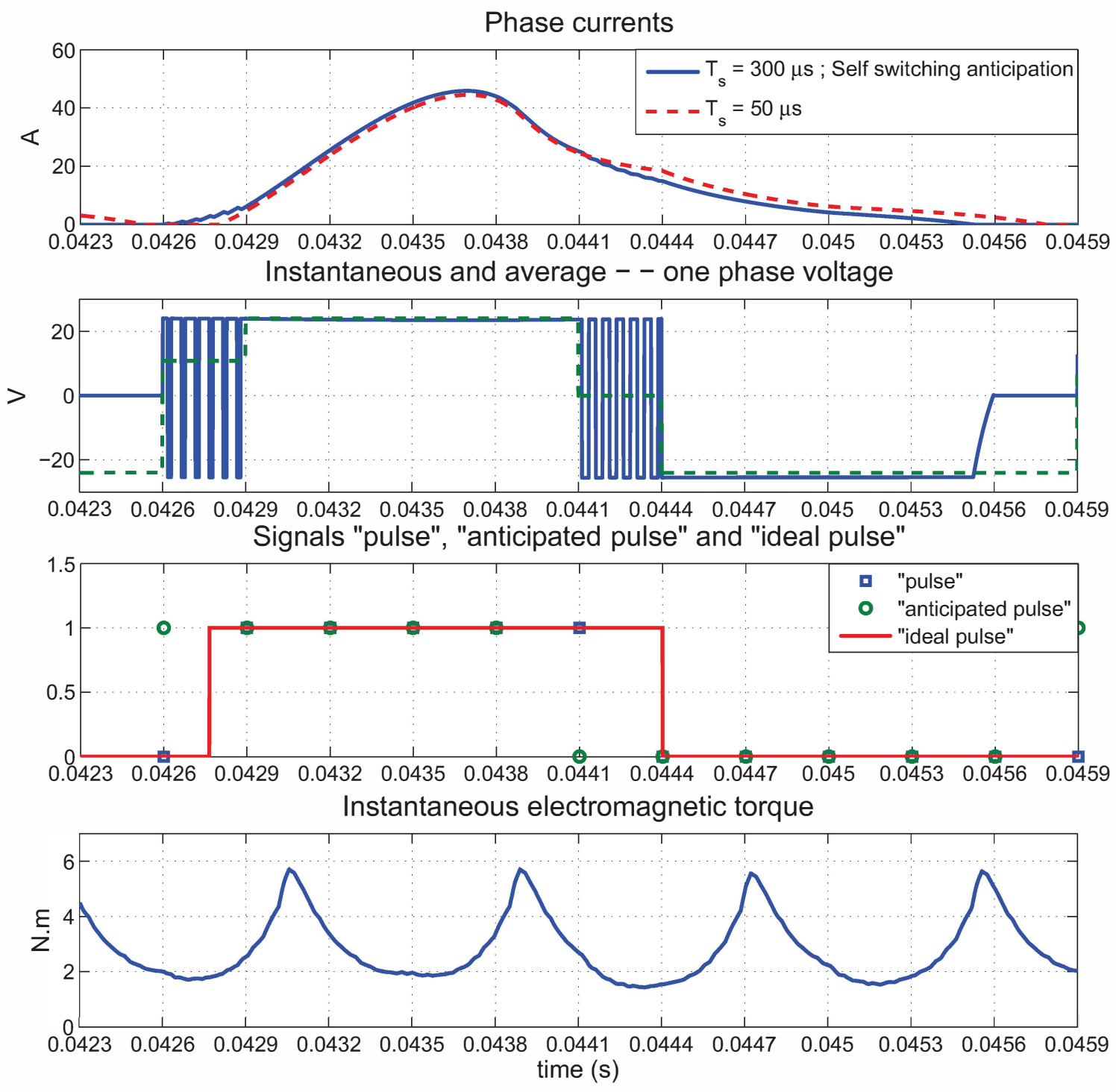

Fig. 8. Phase currents; Instantaneous and average one phase voltage; Variables 'pulse', 'anticipated pulse', 'ideal pulse'; Instantaneous electromagnetic torque $-\Omega=3000 \mathrm{rpm} ; T_{e m}^{*}=3 \mathrm{~N} \cdot \mathrm{m}-T_{s}=300 \mu \mathrm{s}$ and self switching anticipation.

- First step: At time $t[k]$, a logical variable 'pre-pulse a' is set to 1 and a ramp $r$ is generated as shown on Figs. 9 and 10. Moreover, a duty cycle $\alpha$ that represent the distance between the desired firing angle $\theta_{\text {on }}$ and the actual position $\theta_{e}[k]$ is computed as follows:

$$
\alpha=\frac{\theta_{\text {on }}-\theta_{e}[k]}{N_{r} \Omega T_{s}}
$$

Then, a comparison between $\alpha$ and the ramp $r$ generates a logical signal 'pre-pulse b'. The rising edge of this signal correspond to the ideal instant of magnetization $t_{o n}$ and define the firing time of the incoming phase.

- Second step: At time $t[k+1]$, the latter variables fall to zero and the switched logic svstem generator works time (in this case $10 \mathrm{~ns}$ ), and must be therefore implemented on a hardware level (e.g. FPGA).

The same mechanism works for the demagnetization. The duty cycle $\alpha$ is computed as follows:

$$
\alpha=\frac{\theta_{o f f}-\theta_{e}[k]}{N_{r} \Omega T_{s}}
$$

Fig. 11 shows a simulation test, for the operating point $\left(\Omega=3000 \mathrm{rpm} ; T_{e m}^{*}=3 \mathrm{~N} . \mathrm{m}\right)$. The computed estimated angles correspond to ideal firing angles. Therefore, the performances are not degraded despite the fact the sampling time is large.

The proposed method works if the firing angles $\left(\theta_{\text {on }}, \theta_{\text {off }}\right)$ doesn't fall in the sample interval. Therefore, Equ. 9 is indi-

$$
\theta_{\text {off }}-\theta_{\text {on }}>N_{r} \Omega T_{s}
$$




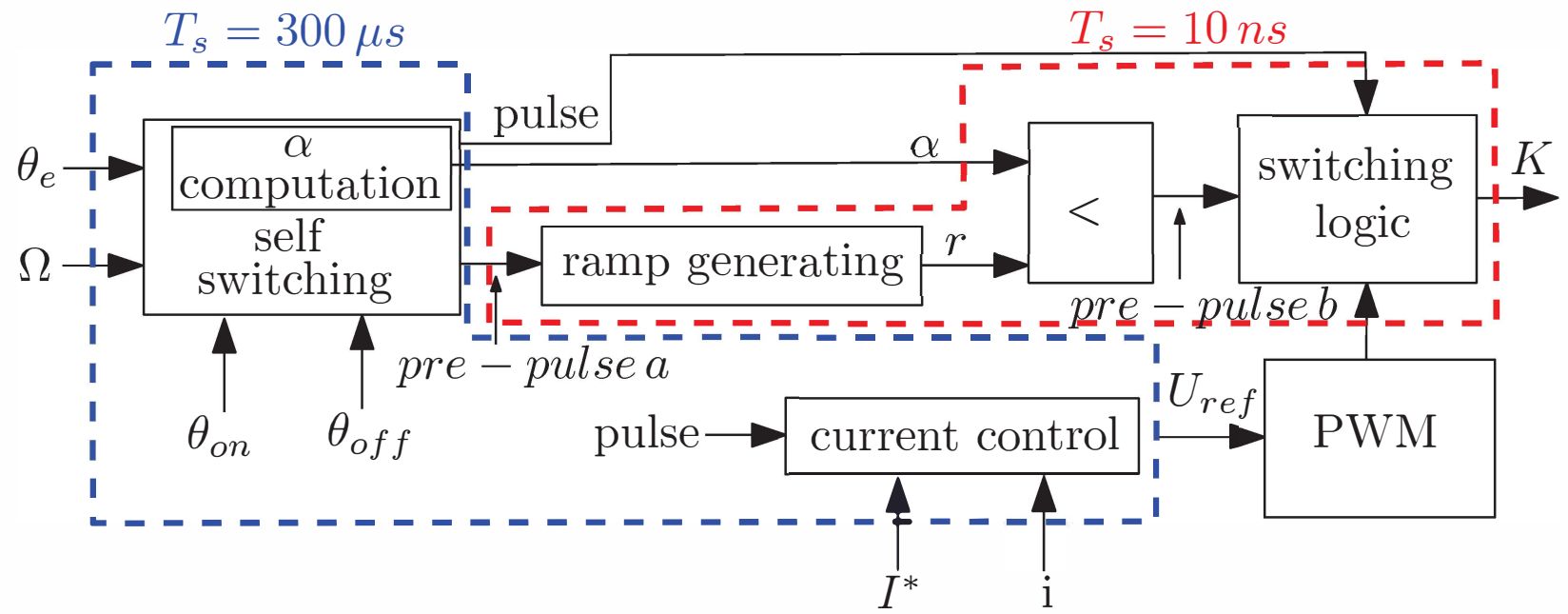

Fig. 9. Principle of the hardware implementation - Block diagram.

Phase currents
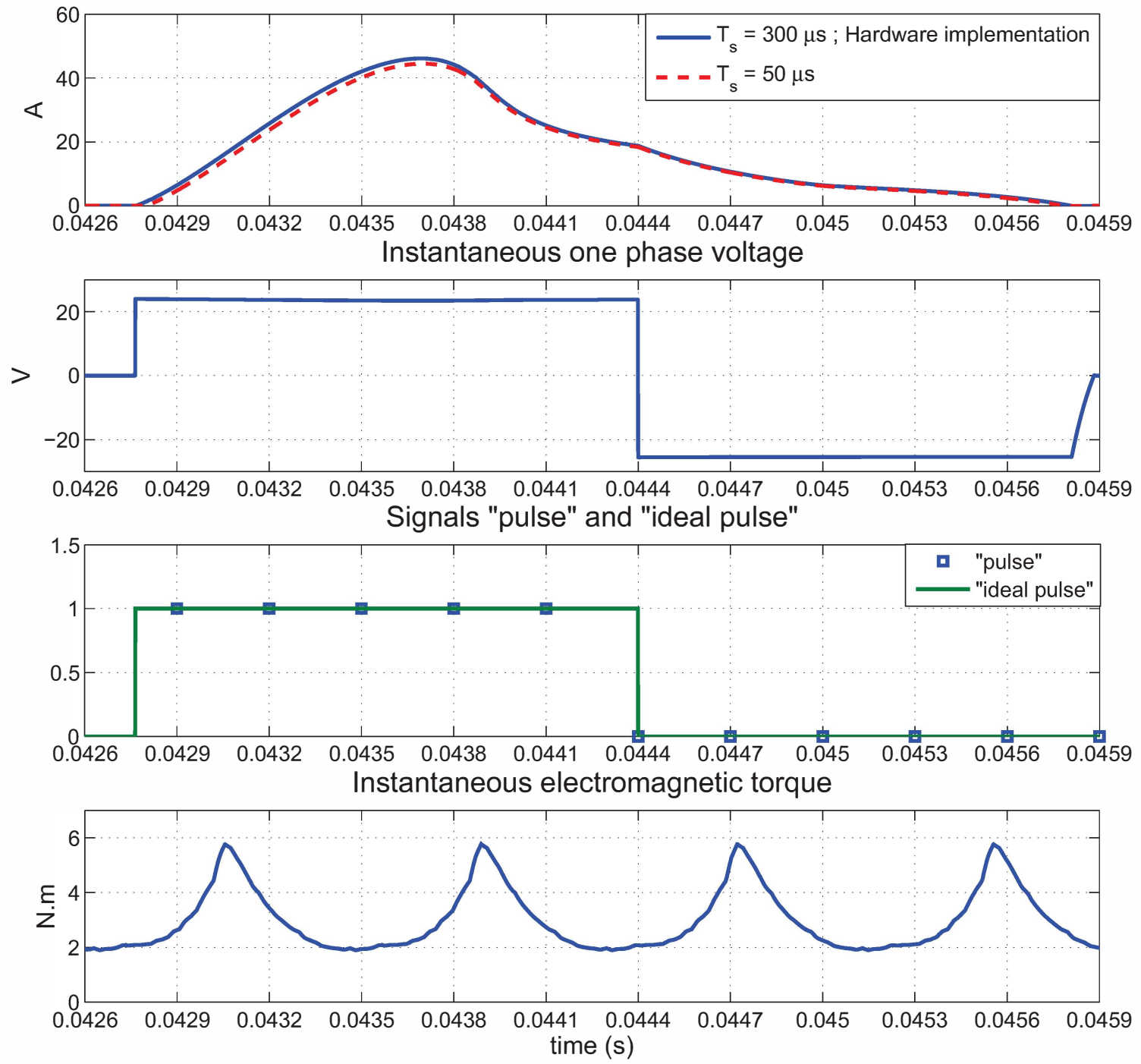


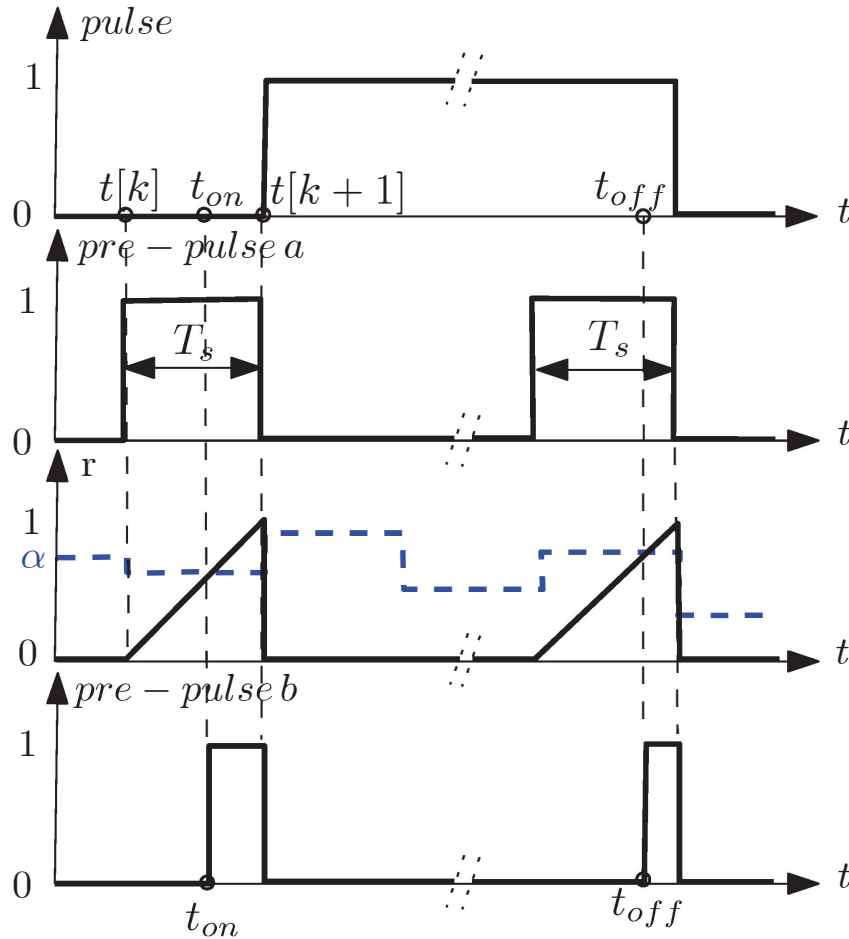

Fig. 10. Principle of the hardware implementation - Timing analysis.

To illustrate this limit, we consider that conduction angle is equal to $180^{\circ}$ and the mechanical speed is equal to $3000 \mathrm{rpm}$. It follows that the theoretically maximum sampling time $T_{s}$ must be lower than $1.67 \mathrm{~ms}$. Therefore, in practice, this relation is always verified.

\section{CONCLUSION}

This paper focus on reducing dramatically the sampling period to save processor real time resources when controlling SRMs. Two solutions are proposed to achieve such goal without degradation of the overall SRM's performance. Two solutions have been developed for the switching signal system generator. The first one consists on an anticipation of the voltage supply at a software level and show some performance improvement on the torque ripple. However, this technique is limited to operate in a wide range of operating speeds. The second one uses a basic function implemented at a hardware level and demonstrate that the SRM's performances does not depend on the sampling period provided that the supply is full wave. Accurate simulation results show the validity of the two proposed novel strategies. Further experimentation is currently under study.

TABLE I

PERFORMANCE COMPARISON

\begin{tabular}{|c|c|c|c|c|}
\hline \multicolumn{5}{|c|}{$n=500 \mathrm{rpm} ; T_{e m}^{*}=10$ N.m } \\
\hline & $T_{s}=50 \mu \mathrm{s}$ & $T_{s}=300 \mu \mathrm{s}$ & $T_{s}=300 \mu \mathrm{s}$ & $T_{s}=300 \mu \mathrm{s}$ \\
\hline$T_{e m}$ & 10.33 N.m & 9.67 N.m & 10.11 N.m & 10.22 N.m \\
\hline$\Delta T_{e m}$ & $20.6 \%$ & $31.8 \%$ & $20.3 \%$ & $18.5 \%$ \\
\hline$\eta$ & $53.3 \%$ & $55 \%$ & $54 \%$ & $54.3 \%$ \\
\hline \multicolumn{5}{|c|}{$\bar{n} n=3000 \mathrm{rpm} ; T_{e m}^{*}=3 \mathrm{~N} . \mathrm{m}$} \\
\hline & $T_{s}=50 \mu \mathrm{s}$ & $T_{s}=300 \mu \mathrm{s}$ & $T_{s}=300 \mu \mathrm{s}$ & $T_{s}=300 \mu \mathrm{s}$ \\
\hline$T_{e m}$ & 2.84 N.m & 2.56 N.m & 2.58 N.m & 2.87 N.m \\
\hline$\Delta T_{e m}$ & $136.9 \%$ & $238.3 \%$ & $167.6 \%$ & $134.7 \%$ \\
\hline$\eta$ & $79 \%$ & $78.4 \%$ & $78.1 \%$ & $79.6 \%$ \\
\hline
\end{tabular}

TABLE II

PROTOTYPE CHARACTERISTICS

\begin{tabular}{|l|l|l|l|}
\hline \multicolumn{4}{|c|}{ Geometric parameters } \\
\hline Number of stator poles & 8 & Stator pole arc & $19.8^{\circ}$ \\
\hline Number of rotor poles & 6 & Rotor pole arc & $20.65^{\circ}$ \\
\hline Stator outer diameter & $143 \mathrm{~mm}$ & Airgap length & $0.8 \mathrm{~mm}$ \\
\hline Rotor outer diameter & $68 \mathrm{~mm}$ & Active length & $125 \mathrm{~mm}$ \\
\hline \hline \multicolumn{3}{|c|}{ Electrical parameters } \\
\hline Number of phases & 4 & Nominal speed & $\begin{array}{l}3000 \\
\text { rpm }\end{array}$ \\
\hline Nominal power & $1.2 \mathrm{~kW}$ & Nominal voltage & $24 \mathrm{~V}$ \\
\hline Phase resistance & $50 \mathrm{~m} \Omega$ & Maximal current & $100 \mathrm{~A}$ \\
\hline
\end{tabular}

\section{REFERENCES}

[1] B. Fahimi, A. Emadi, R.B. Sepe, "A switched reluctance machinebased starter/alternator for more electric cars," IEEE Industry Applications Magazine, Vol. 20, no 1, pp. 116-124, Mar. 2004.

[2] J. Faiz, K. Moayed-Zadeh, "Design of switched reluctance machine for starter/generator of hybrid electric vehicle," Electric Power Systems Research, Elsevier, Vol. 75, no 2-3, pp. 153-160, 2005.

[3] B.A. Kalan, H.C. Lovatt, G. Prout, "Voltage control of switched reluctance machines for hybrid electric vehicles," IEEE Power Electronics Specialists Conference (PESC'02), Vol. 4, pp. 1656-1660, 2002.

[4] M. Krishnamurthy, C.S. Edrington, A. Emadi, P. Asadi, M. Ehsani, B. Fahimi, "Making the case for applications of switched reluctance motor technology in automotive products," IEEE Transactions on Power Electronics, Vol. 21, pp. 659-675, May 2006.

[5] R.T. Naayagi, V. Kamaraj, "Shape optimization of switched reluctance machine for aerospace applications," 31st Annual Conference of IEEE Industrial Electronics Society (IECON'05), Nov. 2005.

[6] A.V. Radun, "High-power density switched reluctance motor drive for aerospace applications," IEEE Transactions on Industry Applications, Vol. 28, no 1 , pp 113-119, 1992

[7] H. Hannoun, M. Hilairet, C. Marchand, "Design of an SRM speed contro strategy for a wide range of operating speeds," IEEE Transactions on Industrial Electronics, Vol. 57, №9, pp. 2911-2921, 2010.

[8] H. Hannoun, M. Hilairet, C. Marchand, "Experimental validation of a switched reluctance machine operating in continuous conduction mode," IEEE Transactions on Vehicular Technology, Vol. 60, № 4, pp. 1453-1460, 2011

[9] X. Rain, M. Hilairet, O. Bethoux, "Comparative study of various current controllers for the switched reluctance machine," IEEE Vehicle Power and Propulsion Conference VPPC, Lille, Septembre 2010.

[10] M. Besbes, B. Multon, "MRVSIM Logiciel de simulation et d'aide à la conception de Machines à réluctance variable à double saillance à alimentation électronique," Dépôt APP CNRS en 2004, $\mathrm{n}^{\circ}$ IDDN.FR.001.430010.000.S.C.2004.000.30645

[11] M. Hilairet, H. Hannoun, C. Marchand, "Design of an optimised SRM control architecture based on a hardware/software partitioning," IEEE International Symposium on Industrial Electronics (IECON'09), Nov. 2009.

[12] E. Monmasson, M.N. Cirstea, "FPGA Design Methodology for IndustrialControl Systems - A Review,'IEEE Transactions on Industrial Electronics, Vol. 54, № 4, pp. 1824-1842, 2007.

[13] G. Espinosa-Perez, P. Maya-Ortiz, M. Velasco-Villa, H. Sira-Raminez, "Passivity-based control of switched reluctance motors with nonlinear magnetic circuits," IEEE Transactions on Control Systems Technology, Vol. 12, no 3, pp. 439-448, may 2004.

[14] R. Ortega, E. Garcia-Canseco, "Interconnection and damping assignment passivity-based control: A survey," European Journal of Control, Vol. 10, pp. 432-450, 2004.

[15] R. Ortega, A. van der Schaft, F. Castanos, A. Astolfi, "Control by Interconnection and Standard Passivity-Based Control of Port-Hamiltonian Systems," IEEE Transactions on Automatic Control, Vol. 53, no. 11, pp. 2527-2542, 2008

[16] S. Monaco, D. Normand-Cyrot, F. Tiefensee, "From passivity under sampling to a new discrete-time passivity concept," Proc. 47th IEEE CDC, pp. 3157-3162, Cancun, 2008.

[17] F. Tiefensee, M. Hilairet, D. Normand-Cyrot, O. Bethoux, "Sampleddata energetic management of a Fuel Cell/Supercapacitor system," Vehicle Power and Propulsion Conference (VPPC), 2010. 